University of Nebraska - Lincoln

DigitalCommons@University of Nebraska - Lincoln

Faculty Publications, Department of Psychology

Psychology, Department of

2003

\title{
Family Factors That Differentiate Sexually Abused and Nonabused Adolescent Psychiatric Inpatients
}

\author{
Dawn H.S. Reinemann \\ University of Wisconsin - Milwaukee \\ Kevin D. Stark \\ University of Texas at Austin \\ Susan M. Swearer Napolitano \\ University of Nebraska-Lincoln, sswearernapolitano1@unl.edu
}

Follow this and additional works at: https://digitalcommons.unl.edu/psychfacpub

Part of the Psychiatry and Psychology Commons

Reinemann, Dawn H.S.; Stark, Kevin D.; and Swearer Napolitano, Susan M., "Family Factors That Differentiate Sexually Abused and Nonabused Adolescent Psychiatric Inpatients" (2003). Faculty Publications, Department of Psychology. 575.

https://digitalcommons.unl.edu/psychfacpub/575

This Article is brought to you for free and open access by the Psychology, Department of at DigitalCommons@University of Nebraska - Lincoln. It has been accepted for inclusion in Faculty Publications, Department of Psychology by an authorized administrator of DigitalCommons@University of Nebraska - Lincoln. 
Published in the Journal of Interpersonal Violence (2003) 18: 471-489. DOI: 10.1177/0886260503251068. http://jiv.sagepub.com/content/18/5/471; Citations: http://jiv.sagepub.com/content/18/5/471. refs.html. Published on behalf of the American Professional Society on the Abuse of Children. Copyright 2003, Sage. Used by permission.

\title{
Family Factors That Differentiate Sexually Abused and Nonab- used Adolescent Psychiatric Inpatients
}

\author{
Dawn H.S. Reinemann ${ }^{1}$, Kevin D. Stark ${ }^{2}$, and Susan M. Swearer ${ }^{3}$ \\ ${ }^{1}$ University of Wisconsin-Milwaukee; ${ }^{2}$ University of Texas at Austin; ${ }^{3}$ University \\ of Nebraska-Lincoln
}

Abstract

Sexual abuse research has traditionally focused on adult, retrospective accounts of potential correlates of abuse and their impact on functioning. However, only a few studies have examined sexually abused adolescents' perceptions of their families, and results have proven inconclusive. This study examined whether family factors would differentiate sexually abused and nonabused adolescent psychiatric inpatients. Fifty-seven psychiatric inpatients, ages 11 to 17, who either had experienced sexual abuse or had no history of sexual victimization completed a diagnostic interview and were assessed on a variety of family indices. Results indicated that after controlling for level of depression, sexually abused adolescents could be differentiated from their nonabused counterparts based on family variables. Sexually abused adolescents reported their families as more authoritarian and more enmeshed. They also perceived more negative messages from their nonoffending father figures about the world. Also, exploratory gender analyses revealed that sexually abused females reported greater levels of depression than sexually abused males.

Keywords: Sexual abuse; Family functioning; Adolescents

Authors'note: Portions of this article were presented at the annual convention of the American Psychological Association, San Francisco, California, August 2001. Please address correspondence to Dawn H. S. Reinemann, University of Wisconsin-Milwaukee, Milwaukee, Wisconsin, USA; dsommer@uwm.edu. Version of record, May 1, 2003. 
Investigators have reported that following sexual abuse, children and adolescents may display a variety of psychological symptoms and behavioral problems (Beitchman, Zucker, Hood, daCosta, \& Akman, 1991; Kendall-Tackett, Williams, \& Finkelhor, 1993). However, existing data also suggest that there is wide variability in youngsters' reactions to sexual victimization and that a significant number of youth do not report elevated levels of psychopathology (Kendall-Tackett et al., 1993). As a result, investigators have sought to examine potential factors that may affect youngsters' adaptation following sexual abuse. This research has traditionally limited its focus to variables such as abuse-specific characteristics (severity, duration, use of force/coercion, etc.) and their impact on subsequent functioning. Results have generally shown that these variables do not account for large amounts of variance in children's and adolescents' psychological functioning (Spaccarelli, 1994).

As a result, researchers have begun to report evidence for the effect of other individual difference variables such as attributional style and coping skills on sexually abused child and adolescent outcomes (Hazzard, Celano, Gould, Lawry, \& Webb, 1995; Wolfe, Gentile, \& Wolfe, 1989). Although a number of theorists postulate that the family environment plays an important role in the development of children's cognitive processing system and psychological functioning (Bandura, 1978; Beck, Rush, Shaw, \& Emery, 1979), little research has focused on the family environments of abuse victims and their impact on adjustment. The gap in the literature in this area may have occurred because investigators were concerned that focusing on family attributes would place blame on nonoffender family members and victims themselves (Hulsey, Sexton, \& Nash, 1992) or would diminish the role of the abuse experience by focusing on the influences of other factors on survivors' psychological adjustment (Draucker, 1996). Recently, investigators have begun to stress the importance of addressing family environment factors within a transactional framework to more carefully examine the multiple interactions that determine the developmental pathway toward healthy or maladaptive outcomes following sexual victimization (Spaccarelli, 1994). However, most work in this area has consisted of studies that focus on adult survivors' retrospective perceptions of their families during childhood.

For example, retrospective investigations of adult survivors of sexual abuse show that they perceive their families as dysfunctional (Bennett, Hughes, \& Luke, 2000). Results also indicate that these families are perceived to be less committed and supportive (Koverola, Proulx, Battle, \& Hanna, 1996), less cohesive and expressive (Kern \& Hastings, 1995), more disorganized (Long \& Jackson, 1994), more conflictual and controlling (Kern \& Hastings, 1995; Koverola et al., 1996), more authoritarian (Hulsey et al., 1992), less active/recreational (Jackson, Calhoun, Amick, Maddever, \& Habif, 1990; Kern \& Hastings, 1995), and more isolated (Hulsey et al., 1992) than families of nonabused persons. Although these findings suggest that there are important differences between the families of sexually abused and nonabused individuals that may affect adjustment, it is likely that adult victims'retrospective reports are negatively biased (Spaccarelli, 1994). According to Draucker (1996), 
many factors may influence adults' perceptions of early family experiences such as current functioning, life events, treatment, and so forth. This is not as much of an issue when the role of family factors is examined during childhood, as less time has elapsed since abuse, and therefore, fewer intervening variables are present that may influence perceptions (Spaccarelli, 1994).

Fewer empirical investigations have directly examined the families of sexual abuse victims in childhood. Initial data suggest that lack of maternal support following abuse disclosure and family dysfunction are linked to increased symptomatology and poorer adjustment (Conte \& Schuerman, 1987). However, a prospective study of child adjustment following sexual victimization revealed that initial family functioning and maternal relationships did not predict children's depression or behavioral problems 5 years after disclosure of the abuse (Tebbutt, Swanston, Oates, \& O'Toole, 1997).

Progress in the study of the family functioning of sexually abused youth has been hampered by methodological limitations that include sampling bias, samples that contain a large age range of participants, lack of appropriate comparison groups, difficulties in defining and operationalizing predictor and criterion variables, use of subjective measures, and inattention to possible confounding factors that should be controlled for through study design or via statistical procedures (Beitchman et al., 1991; Kendall-Tackett et al., 1993; Spaccarelli, 1994). Although researchers have stressed the need to increase the methodological rigor of sexual abuse investigations (Beitchman et al., 1991; Kendall-Tackett et al., 1993) and to include youngsters' appraisals in assessment (Beitchman, et al., 1991; Spaccarelli, 1994), a search of the sexual abuse literature over the past 20 years revealed fewer than 10 studies that compared sexually abused youths'perceptions of their families to that of a nonabused comparison group. Moreover, only two investigations (Hussey \& Singer, 1993; Wherry et al., 1994) specifically examined adolescents, whereas the remaining focused on younger children (Faust, Kenny, \& Runyon, 1997; Stern, Lynch, Oates, O'Toole, \& Cooney, 1995) or included participants ranging from elementary through senior high school (Hoagwood \& Stewart, 1989).

Results indicate that sexually abused children perceive having more negative relationships with their mothers (Stern et al., 1995) and report that their families have poorer problem-solving skills, more role confusion, and maladaptive family functioning (Hoagwood \& Stewart, 1989). In another study of sexually abused and nonabused children suffering from enuresis (repeated voiding of urine during the day or night into bed or clothes), the sexually abused enuretic children reported their families as more conflictual and rigid than their nonabused enuretic counterparts (Faust et al., 1997). However, due to the unique nature of the sample (enuretics), it is uncertain the extent to which the findings can be generalized to other populations of sexually abused youth. Although preliminary data suggest that elementary-aged sexual abuse victims view their families as more dysfunctional than their nonabused counterparts, results of investigations that have focused on the adolescent developmental period appear less conclusive. For example, although Wherry et al. (1994) have reported that family trauma and dysfunction are 
more prevalent among a clinical sample of adolescents who were sexually abused by a nonfamily member versus those who had not been abused, others have failed to find differences between abused and nonabused adolescent inpatients in levels of family cohesion, adaptability, and overall family structure (Hussey \& Singer, 1993).

Not only is there a lack of empirical research that has focused on sexually abused adolescents' perceptions of their families, but also, noticeably absent from most sexual abuse investigations is any mention of the impact of nonoffender father figures on youngsters' adjustment. Given that social support is frequently cited as a factor that buffers the impact of stressful life events (Garmezy, Masten, \& Tellegen, 1984), including abuse, it would appear beneficial to examine the perceived role that other individuals, such as nonoffending paternal figures, play in sexually victimized youngsters' adaptation.

Therefore, the current investigation attempted to fill some of the gaps in the literature and to address various methodological limitations by focusing on the adolescent developmental period, using a semistructured diagnostic interview to assess psychopathology as a potential covariate, including a nonabused comparison group, and by assessing perceptions of both nonoffending maternal and paternal messages about the self, world, and future as potential factors that may differ between sexually abused and nonabused groups. Differences in the family environments of sexually abused and nonabused adolescents have implications for developing programs that attempt to prevent the onset of sexual abuse in those at risk, as well as implications for treatment of youth who have experienced sexual victimization. Based on the theoretical and empirical literature, it was predicted that sexually abused youth would be differentiated from their nonabused counterparts by a number of dysfunctional family characteristics, including more perceived negative messages from caregivers. Exploratory analyses also examined whether there are gender differences in family functioning and depression within abused and nonabused groups.

\section{Method}

\section{Participants}

Participants were 57 adolescents (29 males, 28 females) receiving mental health services in a residential treatment center and who either had experienced sexual abuse ( $n=20,10$ males, 10 females) or had no known history of sexual victimization ( $n=37,19$ males, 18 females). Thus, of the 57 participants, $36 \%$ of females and $34 \%$ of males acknowledged sexual abuse (35\% overall prevalence rate). Adolescents were excluded from the study if they had a history of physical abuse only to reduce the likelihood that the nonabused group would contain adolescents who had experienced a confounding form of abuse. Other exclusionary criteria included the presence of organically based psychological disorders or psychotic disor- 
der, or physical illness. Participants were 11 to 17 years old $(M=14.86, \mathrm{SD}=1.34)$ and in Grades 6 to $12(M=9.14, \mathrm{SD}=1.46)$. Wechsler Intelligence Scale for ChildrenThird Edition (Wechsler, 1991) full-scale IQ scores ranged from 73 to 135 ( $M=$ $100.04, \mathrm{SD}=15.39)$. The majority of youth were Caucasian $(88 \%, n=50), 4 \%$ were Latino, 2\% were African American, and 6\% were biracial.

Family Demographics

Information was obtained for adolescents' living arrangements prior to admission to the treatment center. Less than half $(28 \%, n=16)$ lived with both biological parents, $18 \%(n=10)$ lived with their biological mother, 32\% $(n=18)$ lived with their biological mother and stepfather, $2 \%(n=1)$ lived with their biological father, $8 \%(n=5)$ lived with their biological father and stepmother, $2 \%(n=1)$ lived with grandparents, $7 \%(n=4)$ lived with adoptive parents, and 3\% $(n=2)$ lived with other relatives.

Definition of Sexual Abuse

Sexual abuse was defined as nonconsensual sexual contact of an exploitive nature between a perpetrator and victim younger than age 16 (Mannarino \& Cohen, 1996). Exploitation involved a difference in power between the perpetrator and victim, by way of size, age, and/or the nature of the emotional relationship (Mannarino \& Cohen, 1996).

Sexual Abuse Characteristics

In all, 17 out of $20(85 \%)$ sexually abused adolescents were victimized by offenders who were at least 5 years older than the youths. The other 3 were victimized by offenders of unknown age but were included in the sample due to the involuntary nature and severity of the abuse (in all 3 cases the youth reported being raped). The mean age of onset of abuse was 9.5 years. Also, $40 \%$ (8 total, 7 males, 1 female) of sexually abused adolescents were child protective services-verified perpetrators of sexual abuse in addition to having been victims. Additional descriptive information regarding aspects of sexual abuse is delineated in Table 1.

\section{Instrumentation}

Sexual Abuse Measure

A standard set of abuse-specific questions was added to the post-traumatic stress disorder (PTSD) section of a diagnostic interview, the Schedule for Affective Disorders and Schizophrenia for School Age Children-Epidemiological Version (K-SADS-E) 
(Orvaschel \& Puig-Antich, 1994), to assess sexual abuse experiences (e.g., "When did the abuse occur? Who abused you?"). Following the interview, chart reviews were conducted to verify and gain additional information on the nature of sexual abuse. Youth who experienced sexual victimization were coded (1), and those who were not abused were coded (0).

Table 1

Descriptive Information Regarding the Nature of Sexual Abuse

\begin{tabular}{lcrrrrr} 
& \multicolumn{2}{c}{ Male } & \multicolumn{2}{c}{ Female } & \multicolumn{2}{c}{ Total } \\
Aspect of Sexual Abuse & $\mathrm{n}$ & $\%$ & $\mathrm{n}$ & $\%$ & $\mathrm{n}$ & $\%$ \\
Gender of adolescent & 10 & 50 & 10 & 50 & 20 & 100 \\
Offender & & & & & & \\
Stepfather & 0 & 0 & 3 & 15 & 3 & 15 \\
Foster mother & 1 & 5 & 0 & 0 & 1 & 5 \\
Male relative & 5 & 25 & 2 & 10 & 7 & 35 \\
Female relative & 1 & 5 & 0 & 0 & 1 & 5 \\
Familiar adult male & 3 & 15 & 4 & 20 & 7 & 35 \\
Older male peer & 2 & 10 & 3 & 15 & 5 & 25
\end{tabular}

Number of offenders in child's life

Two

Three or more

Child also a sexual perpetrator

945

210

$\begin{array}{ll}7 & 35\end{array}$

$16 \quad 80$

$0 \quad 0$

$0 \quad 0$

$7 \quad 78$

210

$2 \quad 10$

$1 \quad 14$

840

Age difference between

child and offender

5 years or greater

Unable to determine

$\begin{array}{rrrrrr}10 & 50 & 7 & 35 & 17 & 85 \\ 0 & 0 & 3 & 15 & 3 & 15\end{array}$

Frequency of abuse

Once

$\begin{array}{rrrrrr}5 & 25 & 6 & 30 & 11 & 55 \\ 4 & 20 & 1 & 5 & 5 & 25 \\ 1 & 5 & 3 & 15 & 4 & 20\end{array}$

Two to five times
More than five times

Intrusiveness $^{\mathrm{a}}$ (most extensive)

Least serious (fondling)

Serious (genital touching or

digital penetration)

$2 \quad 10$

1

5

3

15

Very serious (cunnilingus,

fellatio, or intercourse)

210

1

53

15

Unable to determine

$5 \quad 25$

7

35

12

2

a Intrusiveness based on criteria developed by Russell (1983). 


\section{Family Measures}

The Self-Report Measure of Family Functioning for Children (SRMFFC) (Stark, Humphrey, Crook, \& Lewis, 1990) consists of 80 items that require children to indicate on a 5-point scale, from never true (1) to very true (5), the degree to which the item has ever described their family. The SRMFF-C contains three dimensions (relationship, value, and system maintenance) and 15 subscales. The relationship dimension describes various characteristics of the relationships among family members and includes subscales that measure cohesion, expressiveness, conflict, family sociability, disengagement, and role performance. The value dimension describes family values and includes subscales that assess intellectual-cultural orientation, active-recreational orientation, and religious emphasis. The system maintenance dimension describes the management style of the parents and the family's perceptions about who controls their lives. It contains subscales that measure organization, external locus of control, democratic family style, laissez-faire family style, authoritarian family style, and enmeshment. Stark et al. (1990) reported that 12 of the scales have acceptable internal consistency reliability, while the external locus of control, disengagement, and laissez-faire family style scales have questionable reliability. The subscales that comprise each dimension were used in analyses, with higher scores indicating that the family exhibits more of the characteristic.

The Family Messages Measure (FMM) (Stark, Schmidt, \& Joiner, 1996) consists of 36 items that comprise three 12-item subscales and an overall score. Children indicate on a 3-point scale, from never (0) to always (2), the frequency of adaptive and maladaptive messages they receive from a parent regarding view of the self (e.g., "My mother tells me I can't do anything right"), the world (e.g., "My father tells me that the world is a mean place"), and the future (e.g., "My father tells me things aren't going to get any better"). Two parallel versions of the measure have been developed for messages from mothers (FMM-M) and from fathers (FMM-F). The FMM has adequate internal consistency reliability for mothers $\left(r_{\alpha}=0.88\right)$ and fathers $\left(r_{\alpha}\right.$ $=0.89$ ) (Stark et al., 1996). Separate subscale scores for mothers and fathers were analyzed, with higher scores indicative of more positive messages.

In the current study, those adolescents who indicated that they had no contact with a particular parent did not complete the relevant FMM measure. Thus, 7 adolescents did not complete the father version $(n=50)$, and two adolescents did not complete the mother version $(n=55)$. When adolescents indicated that they had a biological parent and a stepparent or live-in parent figure of the same gender, they were asked to complete the FMM measure on the parent figure with whom they felt closest to and had the most contact. An examination of the FMM-M and FMM$\mathrm{F}$ data revealed that all sexually abused adolescents completed the relevant measures on nonoffending parent figures. 
Diagnostic Measure

The K-SADS-E (Orvaschel \& Puig-Antich, 1987, 1994) is a semi-structured clinical interview that is administered to the child and his or her parent(s). The K-SADSE measures the presence and severity of symptoms of Axis I disorders within the Diagnostic and Statistical Manual of Mental Disorders (American Psychiatric Association, 1994). It has acceptable interrater reliability, and a comparison of clinician's diagnoses and K-SADSE diagnoses of mood disorders yielded a kappa of 0.67 (Curry \& Craighead, 1990).

Because an earlier version of the K-SADS-E interview did not provide ratings for levels of symptom severity, the Schedule for Affective Disorders and Schizophrenia for School Age Children-Present Episode (K-SADS-P) (Puig-Antich \& Ryan, 1986) depressive disorders section was integrated into the interview. The present episode version yields scores for the presence and severity of each depressive symptom. Thus, even if youth do not meet criteria for a depressive episode, the number and intensity of symptoms can be examined. The score used in the study was the sum (range $=53$ to 285 ) of the severity ratings for each depression-specific symptom endorsed over the past week. The K-SADS-P has adequate interrater reliability for mood disorders (kappa $=0.83$ for major depression) (Last \& Strauss, 1990). Orvaschel, Puig-Antich, Chambers, Tabrizi, and Johnson (1982) also reported high levels of diagnostic agreement between the K-SADS-P and K-SADS-E $(r=0.86)$. In the present study, the internal consistency reliability using coefficient alpha total depression score was 0.93 .

\section{Procedure}

On admission to the treatment center, the adolescent and his or her primary caregiver were invited to participate. If the primary caregiver consented and the youngster assented, a member of the research team reviewed the adolescent's intake information to determine whether any exclusionary criteria (presence of organically based psychological disorders or a psychotic disorder, etc.) disqualified the youth. If the adolescent qualified as a participant, a second research assistant, blind to participant intake information and diagnoses, interviewed the adolescent with the K-SADS within 1 week of his or her admission. Separate K-SADS interviews also were conducted with the primary caregiver in person or over the phone. Based on a combination of information from the child and parent, a DSMIV (1994) diagnosis was given. This diagnosis was compared to the psychiatrist's intake diagnosis, any discrepancies were discussed, and a final consensus diagnosis was made. 
Training of Interviewers

Doctoral students who were blind to adolescents'intake diagnoses administered the K-SADS interviews. Interviewers were trained until they reached at least $80 \%$ agreement on symptom ratings prior to and systematically throughout the study. Reliability was estimated using a kappa coefficient with a minimum criterion of 0.80 . All interviews were taped, and one fourth were reviewed by raters blind to diagnoses to confirm or disconfirm scores and to ensure continuous interrater reliability. Overall interrater reliability using the kappa statistic was 0.86 .

\section{Consensus Diagnoses}

Following this procedure, 6 participants received a diagnosis of a depressive disorder (5 major depression, 1 depressive disorder not otherwise specified), and 6 were diagnosed with major depression and dysthymic disorder, also known as double depression. Seven adolescents experienced disruptive behavior disorders, while the majority $(n=30)$ evidenced a comorbid depressive disorder and one or more disruptive behavior disorders. Finally, 8 adolescents suffered from PTSD (two PTSD and 6 PTSD plus one or more additional disorders).

\section{Completion of Self-Report Measures}

Following the interviews, participants completed a battery of measures, administered in a counterbalanced order, that assessed family functioning (SRMFF-C), perceived family messages from mother (FMM-M), and perceived family messages from father (FMM-F) and other measures included in a larger study of child psychopathology, while supervised by a graduate research assistant who was blind to the youth's abuse status and diagnoses. Participants with a learning disability had the measures read to them. Assessments were completed within approximately one week of admission to the treatment center to minimize treatment and medication effects.

Results

Preliminary Analyses

Preliminary analyses were conducted to identify demographic and clinical variables that may be confounded with sexual abuse status and should be covaried in 
logistic regression analyses. Preliminary analyses were performed with sexual abuse status as the independent variable and demographic (age, grade, gender, ethnicity, living arrangement) and clinical (IQ, psychiatric diagnoses, substance abuse, and level of depression) characteristics as dependent variables. Analyses revealed no differences between sexually abused and nonabused groups on any demographic indices $(p>0.05)$. Additional analyses revealed that the groups differed on one clinical characteristic: Sexually abused adolescents evidenced greater depression $(M=115.00, \mathrm{SD}=32.66)$ than their nonabused counterparts $(M=96.24$, $\mathrm{SD}=29.04), F(1,55)=4.96, p<0.05$. As a result, depression was covaried in all logistic regression analyses.

Preliminary analyses also examined possible differences between those adolescents who were sexually abused by a family member (intrafamilial abuse, $n=12$ ) and those who were abused by a nonfamily member (extrafamilial abuse, $n=8$ ). There were no significant differences between those who experienced intrafamilial abuse and those who experienced extrafamilial abuse on any demographic variables or clinical characteristics $(p>0.05)$. Likewise, no differences were found between the groups on any of the family measures. Thus, the groups were combined for logistic regression analyses. Although other information regarding abuse-related characteristics is provided descriptively in Table 1, statistical analyses were not computed because the limited sample size would have resulted in uninterpretable results.

\section{Analytic Strategy}

Logistic regression analyses were conducted to determine whether family factors predict sexual abuse status. For all logistic regression analyses, KSADS depression scores were entered in the first block of the equations as a covariate, to control for depression. Family variables (SRMFF-C, FMM-M, or FMM-F) were then entered in the second block of each logistic regression equation to determine if they added significantly to the prediction of sexual abuse status.

\section{Logistic Regression Analyses}

In the first logistic regression analysis, the subscales that make up the system maintenance dimension of the SRMFF-C (enmeshment, authoritarian family style, laissez-faire family style, democratic family style, external locus of control, and organization) were examined. K-SADS depression scores were entered in the first block as a covariate, $X^{2}(1, N=56)=4.36, p<0.05$. The addition of the enmeshment, authoritarian family style, laissez-faire family style, democratic family style, external locus of control, and organization factors, entered in the second block, produced a sizeable improvement in predicting abuse status, $X^{2}(6, N=56)=20.75, p$ $<0.01$. Individual regression coefficients were tested for significance using a Wald statistic. Results revealed that after controlling for level of depression, two family factors contributed to the prediction of sexual abuse: SRMFF-C enmeshment 
(Wald $=4.21, p<0.05)$ and SRMFF-C authoritarian family style (Wald $=7.60, p<$ 0.01 ). Greater family enmeshment and a more authoritarian family style characterized the sexually abused group.

The six subscales that make up the relationship dimension of the SRMFFC (role performance, disengagement, family sociability, conflict, expressiveness, and cohesion) were analyzed in the second logistic regression analysis. After controlling for level of depression, the addition of the role performance, disengagement, family sociability, conflict, expressiveness, and cohesion factors did not significantly increase the prediction of sexual abuse status, $X^{2}(6, N=56)=2.19, p$ $>0.05$. Likewise, the three subscales of the value dimension of the SRMFF-C (intellectual-cultural orientation, active-recreational orientation, and religious emphasis) did not add significantly to the prediction of group membership $X^{2}(3, N$ $=56)=4.71, p>0.05$.

Turning to analyses that examined perceived family messages, results revealed that after controlling for level of depression, the addition of the FMM-F messages about self, the world, and the future added significantly to the prediction of group membership, $X^{2}(3, N=50)=8.84, p<0.05$. Individual regression coefficients tested for significance using a Wald statistic showed that perceived negative messages from fathers about the world (Wald $=4.26, p<0.05$ ) significantly contributed to predicting sexual abuse group membership. A separate logistic regression analysis of the FMM-M messages about self, the world, and the future scores revealed that perceived messages from mothers did not add to the prediction of sexual abuse group membership beyond that of K-SADS depression scores, $X^{2}(3, N=55)=1.00, p>0.05$. A summary of logistic regression analyses is provided in Table 2.

\section{Exploratory Gender Analyses}

Exploratory analyses examined gender differences within the sexually abused and nonabused groups of adolescents. Univariate analyses revealed no significant gender differences within the nonabused group for depression or family indices $(p>0.05)$. Within the sexually abused group, gender differences for depression emerged (K-SADS-P depression score, $F=7.42, p<0.05$ ). Sexually abused females reported significantly higher levels of depression $(M=132.20, \mathrm{SD}=34.95)$ than sexually abused males $(M=97.80, \mathrm{SD}=19.30)$. No gender differences were found within the sexually abused group on any family indices $(p>0.05)$. These findings should be viewed tentatively given the small size of the sample.

\section{Discussion}

The main objective of this study was to examine whether family factors differentiated adolescent psychiatric inpatients with a history of sexual victimization from those with no known history of sexual abuse. Results indicatedthat aftercon- 
trolling foradolescents'level of depression, thoseadolescents who were sexually abused described their families as using a more authoritarian parenting style and as more enmeshed than their nonabused adolescent counterparts. Moreover, perceived negative messages from fathers about the world differentiated the sexually abused youth from the nonabused participants.

Prior investigations that have examined sexually abused and nonabused children's perceptions of their families have reported similar results (Faust et al., 1997; Hoagwood \& Stewart, 1989; Stern et al., 1995). Specifically, it appears that families of sexually abused children exhibit more overall maladaptive family functioning (Hoagwood \& Stewart, 1989; Wherry et al., 1994) and appear to be more conflictual and rigid (Faust et al., 1997). Similarly, in the current study, the sexually abused youth characterized their parents as using a more harsh, punitive parenting style than their nonabused counterparts. They also reported blurred boundaries between family members, a finding consistent with that of Hoagwood and Stewart (1989), who reported that sexually abused children perceived more role confusion in their families than their nonabused peers. Moreover, their findings remained significant regardless of whether the children experienced intrafamilial or extrafamilial abuse. Hoagwood and Stewart suggested that difficulties in maintaining appropriate family boundaries be addressed in treatment regardless of the relationship between the victim and perpetrator. Results of the current study lend additional support for their recommendations. However, it must be stated that the causal pathways between negative family environments and the incidence of sexual abuse have not been delineated at this point in time. It may be that maladaptive family functioning precedes or places children at risk for abuse. However, it may be just as likely that the experience of sexual abuse contributes to greater family dysfunction as the system attempts to cope with a severe stressor (Spaccarelli, 1994). Furthermore, placed within a developmental framework, it appears that there are reciprocal relationships between family and abuse variables that affect the pathway toward adaptive or maladaptive outcomes.

In contrast, the dimensions related to family values and relationships among members failed to predict abuse status. These results are inconsistent with adult retrospective studies (Jackson et al., 1990; Kern \& Hastings, 1995; Koverola et al., 1996). The nonsignificant results obtained in the current study may be due to the homogeneous nature of the clinical sample in which both sexually abused and nonabused youth likely have been exposed to other adversities such as parental psychopathology, marital conflict, and so forth. Congruent with this notion, the means for both the sexually abused and nonabused groups on measures of depression and family functioning indicated greater dysfunction than a nonclinical sample of youth (Stark et al., 1996). Despite all participants appearing to have families characterized by dysfunction, important differences between the families of the sexually abused and nonabused groups emerged. In addition, the finding that 
Table 2

Logistic Regression Analyses of Sexual Abuse Status as a Function of Depression, and SelfReport Measure of Family Functioning for Children, System Maintenance Variables, and Family Messages Measure-Father

\begin{tabular}{|c|c|c|c|c|c|c|}
\hline Variable & B & $\begin{array}{l}\text { Wald } \\
\text { Test }\end{array}$ & $\begin{array}{l}\text { Odds } \\
\text { Ratio }\end{array}$ & $\begin{array}{c}\Delta \text { Block } \\
X^{2}\end{array}$ & $\begin{array}{c}\text { Model } \\
X^{2}\end{array}$ & $d f$ \\
\hline \multicolumn{7}{|l|}{ Block 1} \\
\hline K-SADS & 0.02 & $4.02 *$ & 1.02 & $4.36^{*}$ & & 1 \\
\hline \multicolumn{7}{|l|}{ Block 2} \\
\hline K-SADS & 0.03 & $4.31^{*}$ & 1.03 & & & \\
\hline SRMFF-C Enmesh & 0.29 & $4.21^{*}$ & 1.33 & & & \\
\hline SRMFF-C Auth & 0.41 & $7.60^{* *}$ & 1.51 & & & \\
\hline SRMFF-C Lzfa & 0.02 & 0.02 & 1.02 & & & \\
\hline SRMFF-C Demc & 0.12 & 2.07 & 1.13 & & & \\
\hline SRMFF-C Xloc & 0.00 & 0.00 & 1.00 & & & \\
\hline SRMFF-C Org & -0.15 & 1.22 & 0.86 & $20.75^{* *} 6$ & & \\
\hline All Variables & & & & & $25.11^{* *}$ & 7 \\
\hline \multicolumn{7}{|l|}{ Block 1} \\
\hline K-SADS & 0.02 & $4.54^{*}$ & 1.02 & $5.04^{*}$ & & 1 \\
\hline \multicolumn{7}{|l|}{ Block 2} \\
\hline K-SADS & 0.02 & $3.39^{*}$ & 1.02 & & & \\
\hline FMM-F Slf & 0.18 & 1.64 & 1.19 & & & \\
\hline FMM-F Wld & -0.44 & $4.26^{*}$ & 0.64 & & & \\
\hline FMM-F Fut & 0.03 & 0.04 & 1.03 & $8.84^{*}$ & & 3 \\
\hline All Variables & & & & & $13.88^{* *}$ & 4 \\
\hline
\end{tabular}

Note: K-SADS = Depression scale of the Schedule for Affective Disorders and Schizophrenia for School-Age Children-Present Episode; SRMFF-C = Self-Report Measure of Family Functioning for Children; SRMFF-C Enmesh = enmeshment; SRMFF-C Auth = authoritarian family style; SRMFF-C Lzfa = laissez-faire family style; SRMFF-C Demc $=$ democratic family style; SRMFF-C Xloc = external locus of control; SRMFF-C Org = organization; FMM-F = Family Messages Measure- Father; FMM-F Slf = about self; FMM-F Wld = about the world; FMM-F Fut = about the future.

${ }^{*} p<0.05 .{ }^{* *} p<0.01$, two-tailed.

characteristics related to family values and relationships among members did not predict abuse status could be related to the adolescent developmental period itself. During this time, teenagers become more peer focused and may be less likely to engage in recreational activities with their families. Adolescents also are attempting to master the task of identity development and are more likely to experi- 
ment and try on different roles, religions, and so forth. Therefore, these family dimensions may be less likely to discriminate between groups during adolescence. Most research that has found differences between sexually abused and nonabused individuals on these dimensions has used adult populations that may not generalize to the current sample of youth.

Results of the current investigation also found that perceived negative messages sent by father figures predicted those who were sexually abused, while perceived messages from mothers failed to discriminate between groups. Specifically, adolescents who were sexually abused indicated that their father figures sent them more negative messages about the world than their nonabused peers. Results lend partial support to existing theory and research that proposes that the messages that are communicated to children by their parent figures affect youngsters' developing cognitive schema and contribute to the development of psychopathology (Beck et al., 1979; Stark, Humphrey, Laurent, Livingston, \& Christopher, 1993). The finding that perceived messages from mothers about the self, world, and future failed to differentiate the sexually abused and nonabused groups of adolescents is inconsistent with research that has shown that severe abuse is related to more negative perceptions of mothers (Stern et al., 1995). However, again it is likely that family disturbances characterize both sexually abused and nonabused adolescents in treatment, obscuring differences that may be evident in less disturbed populations of youth.

Although causal relationships were not examined, results of this study support the notion that sexually abused adolescents experience negative messages from their nonoffending father figures. Reasons why the sexually abused adolescents reported more negative messages from father figures include the possibility that father figures are behaving in ways that communicate negative messages or are unsure/apprehensive when interacting with adolescents who have been sexually abused. On the other hand, sexually abused adolescents who were victimized by a male may have developed negative perceptions of male figures in general and may interpret messages and interactions with them in a negative light. Although research has emphasized the role that maternal support plays in children's adjustment following abuse (Conte \& Schuerman, 1987), current results suggest that nonoffender father figures also have an impact on sexually abused youths' adjustment and should be included in research designs and treatment.

Finally, sexually abused females reported greater levels of depression than sexually abused males. Although some researchers report no gender differences in symptom levels of sexually abused youth (Kendall-Tackett et al., 1993), others indicate that sexually abused girls exhibit greater depression than sexually abused boys (Darves-Bornoz, Choquet, Ledoux, Gasquet, \& Manfredi, 1998). Females may be more likely to react to abuse with depression because they experience more serious forms of abuse (Cutler \& Nolen-Hoeksema, 1991) and are more likely to be 
abused by a family member than males (Finkelhor, 1979). Unfortunately, sample size prevented an investigation of abuse-specific variables that may have differed between the sexes. In addition, sexual perpetration status may have contributed to gender differences in depression. Although 7 of the 10 sexually abused boys were classified as sexual perpetrators (70\%), only 1 girl in the study had a history of perpetration $(10 \%)$. Thus, the sexually abused boys may be an atypical group, placed in treatment for their perpetration, while the sexually abused girls may have been admitted for psychological symptoms. However, an examination of the impact of perpetration on depression revealed no differences between perpetrators and nonperpetrators.

It is important to consider the findings of this study in the context of its limitations. The exploratory nature of the study and employment of multiple analyses communicates that results obtained be replicated. The cross-sectional and retrospective research design prohibits investigators from drawing conclusions regarding the direction of the relationships between family factors and abuse status. In addition, the study used self-report measures of family functioning, which may not reflect behavior in real-life settings. Generalizability is limited to other adolescent psychiatric populations and by the exclusion of youth who solely experienced physical abuse. Although this was done to reduce the likelihood that the nonabused group would contain adolescents who experienced a confounding type of abuse, it would be beneficial for future investigations to examine characteristics that may distinguish the families of those who have suffered from different forms of victimization. The relatively limited sample size prevented the investigators from examining other potentially important variables such as abuse-specific characteristics that may have affected results. Related, adolescents who experienced intrafamilial and extrafamilial abuse were combined in the investigation to increase sample size. Although trends suggested that there were no significant differences on this variable, larger samples may reveal that there are important differences between those abused by a family member versus those abused by someone outside of the family.

Recognizing the limitations of this investigation, results indicate that even in a more pathological clinical sample, sexually abused adolescents could be differentiated from their nonabused counterparts on family factors including authoritarian parenting style, enmeshment, and negative messages about the world from nonoffending father figures. These results have implications for the treatment of sexually abused youth and their families. It appears important for therapists to address the parenting styles and boundaries between family members in a comprehensive treatment package that targets all members of the family system following one member's sexual victimization. This may include parent training in positive behavior management, family decision making, effective communication, and appropriate roles for family members. Furthermore, findings highlight the poten- 
tial utility of including nonoffender father figures in treatment and targeting the messages that important sources of support send to victims about themselves, the world, and the future. Related, if evidence indicates that sexually abused adolescents have developed negative views of males, treatment may include cognitive restructuring techniques designed to help the youth more accurately interpret messages from paternal figures. Finally, results bring attention to the risk to sexually abused adolescents, and in particular, to sexually abused females, of developing depression. Thus, treatment for sexually abused youth that includes interventions that target the cognitive, behavioral, and affective disturbances associated with depression may prove beneficial.

\section{References}

American Psychiatric Association. (1994). Diagnostic and Statistical Manual of Mental Disorders ( $4^{\text {th }}$ ed.). Washington, DC.: Author.

Bandura, A. (1978). The self system in reciprocal determinism. American Psychologist, 33, 344-358.

Beck, A. T., Rush, A. J., Shaw, B. F., \& Emery, G. (1979). Cognitive Therapy of Depression. New York: Guilford.

Beitchman, J. H., Zucker, K. J., Hood, J. E., daCosta, G. A., \& Akman, D. (1991). A review of the short-term effects of child sexual abuse. Child Abuse and Neglect, 15, 537-556.

Bennett, S. E., Hughes, H. M., \& Luke, D. A. (2000). Heterogeneity in patterns of child sexual abuse, family functioning, and long-term adjustment. Journal of Interpersonal Violence, 15, 134-157.

Conte, J. R., \& Schuerman, J. R. (1987). Factors associated with an increased impact of child sexual abuse. Child Abuse and Neglect, 11, 201-211.

Curry, J. F., \& Craighead, W. E. (1990). Attributional style in clinically depressed and conduct disordered adolescents. Journal of Consulting and Clinical Psychology, 58, 109-115.

Cutler, S. E., \& Nolen-Hoeksema, S. (1991). Accounting for sex differences in depression through female victimization: Childhood sexual abuse. Sex Roles, 24, 425-437.

Darves-Bornoz, J. M., Choquet, M., Ledoux, S., Gasquet, I., \& Manfredi, R. (1998). Gender differences in symptoms of adolescents reporting sexual assault. Social Psychiatry and Psychiatric Epidemiology, 33, 111-117.

Draucker, C. B. (1996). Family-of-origin variables and adult female survivors of childhood sexual abuse: A review of the research. Journal of Child Sexual Abuse, 5, 35-63. 
Faust, J., Kenny, M. C., \& Runyon, M. K. (1997). Differences in family functioning of sexually abused vs. nonabused enuretics. Journal of Family Violence, 12, 405-416. Finkelhor, D. (1979). Sexually Victimized Children. New York: Free Press.

Garmezy, N., Masten, A., \& Tellegen, A. (1984). The study of stress and competence in children: A building block for developmental psychopathology. Child Development, 55, 97-111.

Hazzard, A., Celano, M., Gould, J., Lawry, S., \& Webb, C. (1995). Predicting symptomatology and self-blame among child sex abuse victims. Child Abuse and Neglect, 19, 707-714.

Hoagwood, K., \& Stewart, J. M. (1989). Sexually abused children's perceptions of family functioning. Child and Adolescent Social Work, 6, 139-149.

Hulsey, T. L., Sexton, M. C., \& Nash, M. R. (1992). Perceptions of family functioning and the occurrence of childhood sexual abuse. Bulletin of the Menninger Clinic, 56, 438-450.

Hussey, D. L., \& Singer, M. (1993). Psychological distress, problem behaviors, and family functioning of sexually abused adolescent inpatients. Journal of the American Academy of Child and Adolescent Psychiatry, 32, 954-961.

Jackson, J. L., Calhoun, K. S., Amick, A. E., Maddever, H. M., \& Habif, V. L. (1990). Young adult women who report childhood intrafamilial sexual abuse: Subsequent adjustment. Archives of Sexual Behavior, 19, 211-221.

Kendall-Tackett, K. A., Williams, L. M., \& Finkelhor, D. (1993). Impact of sexual abuse on children: A review and synthesis of recent empirical studies. Psychological Bulletin, 113, 164-180.

Kern, J. M., \& Hastings, T. (1995). Differential family environments of bulimics and victims of childhood sexual abuse: Achievement orientation. Journal of Clinical Psychology, 51, 499-506.

Koverola, C., Proulx, J., Battle, P., \& Hanna, C. (1996). Family functioning as predictors of distress in revictimized sexual abuse survivors. Journal of Interpersonal Violence, 11, 263-280.

Last, C. G., \& Strauss, C. C. (1990). School refusal in anxiety disordered children and adolescents. Journal of the American Academy of Child and Adolescent Psychiatry, 29, 31-35.

Long, P. J., \& Jackson, J. L. (1994). Childhood sexual abuse: An examination of family functioning. Journal of Interpersonal Violence, 9, 270-277.

Mannarino, A. P., \& Cohen, J. A. (1996). Family-related variables and psychological symptom formation in sexually abused girls. Journal of Child Sexual Abuse, 5, 105-120.

Orvaschel, H., \& Puig-Antich, J. H. (1987). Schedule for Affective Disorders and Schizophrenia for School-Age Children (Epidemiologic version, $4^{\text {th }}$ ed.). Pittsburgh, Pa.: Western Psychiatric Institute and Clinic. 
Orvaschel, H., \& Puig-Antich, J. H. (1994). Schedule for Affective Disorders and Schizophrenia for School-Age Children (Epidemiologic version, $5^{\text {th }}$ ed.). Pittsburgh, Pa.: Western Psychiatric Institute and Clinic.

Orvaschel, H., Puig-Antich, J., Chambers, W., Tabrizi, M. A., \& Johnson, R. (1982). Retrospective assessment of prepubertal major depression with the Kiddie-SADSE. Journal of the American Academy of Child Psychiatry, 21, 392-397.

Puig-Antich, J., \& Ryan, N. (1986). Schedule for Affective Disorders and Schizophrenia for School-Age Children (Present episode version, 4th working draft). Pittsburgh, Pa.: Western Psychiatric Institute and Clinic.

Russell, D. (1983). The incidence and prevalence of intrafamilial and extrafamilial sexual abuse of female children. Child Abuse and Neglect, 7, 133-146.

Spaccarelli, S. (1994). Stress, appraisal, and coping in child sexual abuse: A theoretical and empirical review. Psychological Bulletin, 116, 340-362.

Stark, K. D., Humphrey, L. L., Crook, K., \& Lewis, K. (1990). Perceived family environments of depressed and anxious children: Child's and maternal figure's perspectives. Journal of Abnormal Child Psychology, 18, 527-547.

Stark, K. D., Humphrey, L. L., Laurent, J., Livingston, R., \& Christopher, J. (1993). Cognitive, behavioral, and family factors in the differentiation of depressive and anxiety disorders during childhood. Journal of Consulting and Clinical Psychology, $61,878-886$.

Stark, K. D., Schmidt, K. L., Joiner, T. E., Jr. (1996). Cognitive triad: Relationship of depressive symptoms, parents' cognitive triad, and perceived parental messages. Journal of Abnormal Child Psychology, 24, 615-631.

Stern, A. E., Lynch, D. L., Oates, R. K., O'Toole, B. I., \& Cooney, G. (1995). Self-esteem, depression, behavior and family functioning in sexually abused children. Journal of Child Psychology and Psychiatry, 36, 1,077-1,089.

Tebbutt, J., Swanston, H., Oates, R. K., \& O'Toole, B. I. (1997). Five years after child sexual abuse: Persisting dysfunction and problems of prediction. Journal of the American Academy of Child and Adolescent Psychiatry, 36, 330-339.

Wechsler, D. (1991). Wechsler Intelligence Scale for Children-Third Edition. San Antonio, Tex.: Psychological Corporation.

Wherry, J. N., Jolly, J. B., Aruffo, J. F., Gillette, G., Vaught, L., \& Metheny, R. (1994). Family trauma and dysfunction in sexually abused female adolescent psychiatric and control groups. Journal of Child Sexual Abuse, 3, 53-65.

Wolfe, V. V., Gentile, C., \& Wolfe, D. A. (1989). The impact of sexual abuse on children: A PTSD formulation. Behavior Therapy, 20, 215-228.

Dawn H. S. Reinemann, Ph.D., is an assistant professor of educational psychology at the University of Wisconsin-Milwaukee. Her research and clinical interests include the short-and long-term impact of traumatic life events on youth, 
risk and resiliency in children and adolescents, childhood depression and comorbidity, and cognitive-behavioral treatment of childhood psychopathology. She is also a certified school psychologist in the state of Wisconsin.

Kevin D. Stark, Ph.D., is a professor of educational psychology at the University of Texas at Austin. His research and clinical interests are centered primarily on childhood depression and cognitive-behavioral therapies for children. He has published work related to the treatment of depressed youths and on a comprehensive model of depressive disorders in youths. He is also the recipient of a National Institute of Mental Health grant designed to develop and evaluate a school-based treatment program for depressed girls.

Susan M. Swearer, Ph.D., is an assistant professor of school psychology at the University of Nebraska-Lincoln and a Gallup research professor in the Gallup Research Center. Her research and clinical interests include the comorbidity of psychological disorders in children and adolescents, developmental issues in psychopathology, the relationship of internalizing psychopathology on externalizing behavior, and cognitive-behavioral interventions with youth and their families. Swearer is a licensed psychologist in the state of Nebraska and is a supervising psychologist in the Counseling and School Psychology Clinic and the Anxiety Disorders Clinic at University of Nebraska-Lincoln. 